\title{
LA REPRESENTACIÓN MEDIÁTICA DE LAS MIGRACIONES EN LA PRENSA ESPAÑOLA DURANTE LA PANDEMIA
}

Ariet Castillo Fernández

Universidad de Granada

\section{RESUMEN}

Este textoanaliza el tratamiento delas migraciones en la prensa española - particularmente en El País y El Mundo-durante los primeros meses de la pandemia, circunscribiéndose a las personas migrantes que llegan de manera irregular. El estudio indaga los términos utilizados para designarles, las formas como se relatan estos hechos sociales, así como qué tipo de imágenes y discursos se proyectan. Para ello, la metodología utilizada ha sido el análisis crítico del discurso en los citados periódicos de tirada nacional y de gran difusión, poniendo atención en asuntos de alteridad, identidad y construcción de la diferencia. También se han analizado algunos artículos de tirada local, dadas las escasas búsquedas localizadas en los considerados principales en el estudio. El análisis evidencia que, aun si la migración en condiciones administrativas irregulares sigue conceptualizándose como un problema, se generan también discursos que ven al emigrante como víctima, especialmente porque su situación pone de relieve las limitaciones e incongruencias del Estado. La crisis experimentada con motivo de la covid-19 convierte también al extranjero en un recurso y a la emigración en una oportunidad, en un contexto en que se piensa la pandemia como un momento para reconfigurar viejas problemáticas.

Palabras clave: Covid-19; Fenómeno migratorio; Pandemia; Población extranjera; Representación mediática; Prensa española. 


\section{ABSTRACT}

This text analyzes the treatment of migration in the Spanish press - particularly in $E l$ País and El Mundo - during the first few months of the pandemic, focusing specifically on the arrival of undocumented migrants. The study investigates the terminology used to refer to these people, the ways in which these social events are related and, in general, the type of images and discourses projected. The methodology used is critical analysis of the discourse presented in the aforementioned national newspapers, which have high readership figures, paying close attention to matters of otherness, identity, and construction of difference. Articles from the local press have also been analyzed, due to the low number of searches located in the major newspapers considered in this study. The analysis shows that, even though undocumented migration is still conceptualized as a problem, discourses are also being generated portraying the immigrant as a victim, especially because their situation highlights the limitations and inconsistencies of the State. The crisis experienced due to Covid-19 also turns foreigners into a resource and immigration into an opportunity, in a context in which the pandemic is thought of as a time to reconfigure previous problems.

Keywords: Covid-19; Migratory phenomenon; Pandemic; Foreign population; Media representation; Spanish press.

\section{PROBLEMÁTICA, PRESUPUESTOS Y METODOLOGÍA ${ }^{1}$}

Nos encontramos ante una situación extraordinariamente extraña. Valga la recurrencia del prefijo ex, cuyo significado vendría a ser "fuera o más allá". Merece mención la vivencia excéntrica que estamos experimentando. En este texto prestamos atención a la población "extranjera", la denominada "foránea", "de fuera”. Analizaremos de qué modo es representada en los medios de comunicación en tiempos de crisis sanitaria global, centrándonos en la prensa nacional española ya que, desde la antropología, nos interesan los estudios sobre alteridad, esa "otredad" inserta en las representaciones sociales y que construye diferencia en los discursos mediáticos.

Partimos de lo que podría llamarse "la información de la desinformación", y de una "incertidumbre fabricada", de la que habla Ulrich Beck (1998) en su Sociedad del riesgo, haciendo mención a los riesgos que se suceden en los procesos humanos que, sin

1. Mis más sinceros agradecimientos a los revisores anónimos que han tenido a bien leer este artículo además de brindarme todas las consideraciones para su mejora. Sus aportaciones me han ayudado mucho a la hora de redactar la versión final. Asimismo, quiero agradecer enormemente el esfuerzo y disposición de Alberto del Campo Tejedor, el editor, por ofrecerme los recursos precisos para alcanzar este resultado preliminar de investigación sin los cuales todo habría sido mucho más complicado. 
embargo, estarían dirigidos a controlar tales amenazas. ¿Qué ocurre cuando hablamos del fenómeno migratorio y su relación con la Covid-19, en específico? ¿Cómo se informa o desinforma en los medios de comunicación? ¿Cómo se vinculan a estos hechos sociales el miedo, el riesgo, la incertidumbre? Estas son las preguntas que suscitaron esta investigación y que se llevaron a término en el análisis de la prensa escrita española.

En el contexto actual, en tiempos del coronavirus, abundan las predicciones y hay infinidad de "virólogos de salón de casa”. ¿Estamos viviendo una catástrofe? Por supuesto que lo es, no cabe duda, pues contemplamos muchas personas enfermas y muchas muertes diarias. Nos ceñimos a estadísticas y ¡cuidado con ellas! Como se suele decir, "si no son cuentas, son cuentos". Una alusión, por otro lado, bien cuantitativa. Conviene, sin embargo, no despreciar los análisis cualitativos que también pueden arrojar luz sobre las circunstancias sociales en torno a la pandemia, y es a ello a lo que vamos a atender.

La posmodernidad es auto-reflexiva y con tendencia social a la autocrítica, y por otra parte se asocia a la fiabilidad y el riesgo (Beck, 1998). ¿Disponemos de informaciones fiables que contribuirían a minimizar la situación de incertidumbre? Considerando a Giddens (1997: 46):

"La reflexión de la vida social moderna consiste en el hecho de que las prácticas sociales son examinadas constantemente y reformadas a la luz de nueva información sobre esas mismas prácticas, que de esa manera alteran su carácter constituyente”.

Vivimos en una sociedad global; tanto la información, la comunicación, como todo lo relativo al ámbito económico y de mercado, indican que formamos parte de una sociedad mundial. El riesgo global forma parte de la sociedad en la que convivimos. Los riesgos derivados del desarrollo científico y tecnológico son la fuente de nuevos problemas en la sociedad actual. Desde las tesis desarrolladas por Ulrich Beck (1998) en La sociedad del riesgo, el individuo aloja su confianza en ámbitos que son, eminentemente, políticos y científicos.

Por su parte, Luhmann (apud Galindo, 2015) expone que, como diría Max Weber, si la acción es social, el único fenómeno puramente relacional es la comunicación, lo que nos compete directamente en este estudio de las migraciones desde la prensa escrita en España. Al hilo, merece mención Parsons, pues hablar de tal asunto remite a la situación de doble contingencia que se presenta cuando, al menos, dos individuos entran en contacto. Este concepto alude a la incertidumbre que cada individuo manifiesta respecto al comportamiento del otro. Como dijera Díaz de Rada (2010), la persona es el “individuo-en-relación". Sin embargo, en muchos casos no interactuamos directamente con individuos o colectivos, lo que no nos priva de desarrollar ideas, imágenes sobre ellos, frecuentemente mediadas por los discursos que nos llegan. 
He aquí donde retomamos las consideraciones del comienzo, donde hacíamos mención a esos otros, ciertamente extraños y que, por ello, se nos hacen lejanos. Desde la vinculación entre medios de comunicación y migraciones, merece mención Bañón (2014) y sus estudios sobre grupismo donde entra en consideración el denominado "exogrupo", que aloja esta idea de que los sujetos vinculados con las migraciones se tratan como un sujeto colectivo, que no sería diverso sino homogéneo. Lejos de tratar la diversidad, se toma en cuenta la construcción de la diferencia y su desencadenante, que es la desigualdad desde la que se trasladan discursos de odio y estigmatizaciones sociales hacia la población migrante. Se trata de una reificación de las personas protagonistas de las migraciones. Tanto es así que se perpetúa una mirada que problematiza las migraciones, puesto que presenta la (in)migración como amenaza donde los sujetos migrantes son "otros". Amenaza que se ve fortalecida por esa condición de considerar a los sujetos desde ese grupismo al que se hace mención, lo que desprende estigmas como las asociaciones relacionadas con delincuencia, hurtos o inseguridad.

También, al respecto y en cuanto a las poblaciones y estudios demográficos, merece mención Domingo (2018) dado que nos interesa cómo, en las noticias sobre migraciones vinculadas con la pandemia, se visibilizan ciertos estereotipos sobre la evolución de la población.

Pensando desde la antropología, son los fundamentos de la etnografía los que nos hacen pensar en el todo, y no solo en sus partes, sino en su contexto. Es esta última noción la que no podemos olvidar, el contexto, bien hablemos de datos cuantitativos, ya tratemos de información cualitativa. Importa cómo se contextualizan las informaciones y a qué elementos se asocian. Es igualmente relevante plantear los relatos explícitos e implícitos en las noticias y cómo estas se vuelven constructos sociales con efectos reales. Como enunciaría Beck, los riesgos se conforman si se definen como tales. El riesgo es ubicuo, invade, por tanto, todas las esferas de la vida social. Siendo así, se trata de un "hecho social total" (Mauss, 2009), que tiene también una dimensión comunicativa.

¿De qué modo se representa el fenómeno migratorio en los medios de comunicación de prensa escrita española en relación con el coronavirus? Desde un estudio de los acontecimientos ocurridos en torno a las migraciones, indagamos cómo se nombran y cómo se relatan estos asuntos. ¿Se incrementa la supuesta problemática del fenómeno migratorio a consecuencia de la situación de crisis sanitaria? Veremos cómo se construye la diferencia partiendo de cómo cuenta la prensa española, las migraciones. Nos interesa particularmente indagar si el discurso mediático sobre el fenómeno migratorio en el contexto de la pandemia se relaciona con la construcción de prejuicios y estigmas sociales.

Zizek, en su nueva publicación Pandemic! (2020), plantea que la crisis sanitaria a la que nos enfrentamos desvela la debilidad del mundo globalizado y hace plantearse una recuperación de lo común. Si no sostenemos tal "comunismo del siglo XXI", caeremos 
en la barbarie. Si hablamos de gobernanza y de la posible relación entre migraciones y pandemia, así como de las lecturas que se llevan a término en los medios de comunicación, no podemos olvidar a la filósofa Cortina (2017) en tanto en cuanto alude a un desafío, como es el de considerar ciertos anhelos y posibles carencias que acompañan a los estados-nación en un nivel internacional (2017: 250):

"El éxodo de los inmigrantes económicos y de los refugiados políticos es uno de los mayores desafíos a los que nos enfrentamos en nuestro mundo globalizado; un problema que se plantea en el mesonivel de las instituciones nacionales, las españolas en nuestro caso, de la Unión Europea como unión supranacional, y en el macronivel de las instituciones internacionales, de tal modo que no hay solución posible si no es con un trabajo conjunto".

Partimos en este texto de la necesidad de potenciar el pensamiento y la reflexión crítica para que la representación social de la población extranjera se aleje de procesos clasificatorios y estigmatizadores de la población migrante y el fenómeno migratorio.

Dado que nos interesa cómo se vinculan las migraciones y la pandemia y, en concreto, cómo es representada esta población extranjera en los medios de comunicación en cuestiones que atañen a la situación sanitaria del covid-19, en cuanto al método, hemos visto oportuno el análisis crítico del discurso de Van Dijk (2010), idóneo para el análisis de la representación discursiva de la alteridad, la otredad y la construcción de la diferencia. Para la realización del presente trabajo se han seleccionado y analizado artículos de prensa de dos medios españoles, El País y El Mundo. Esta selección responde a tres razones: son periódicos de tirada nacional, tienen un gran alcance y difusión, y responden a líneas editoriales e ideologías diferentes, con lectores igualmente diferenciados. Además de estos dos diarios, hemos también otros documentos de tirada nacional o local.

Importa mencionar que para el estudio nos hemos servido de la base de datos y buscador de noticias de ediciones online e impresas $M y$ News, de la Hemeroteca digital de prensa de España, facilitada, en este caso, por la Universidad de Granada. Se han tomado en cuenta los términos de búsqueda de "migración", "migraciones", "fenómeno migratorio", "Covid", "Covid-19", "coronavirus", "pandemia", "crisis" y "España”, para el periodo transcurrido entre el primer y último día del primer estado de alarma en España; esto es, desde el 14 de marzo de 2020 hasta el 20 de junio del mismo año, para así atender al interés del estudio y la vinculación entre la representación mediática de las migraciones en el período inicial de pandemia de la Covid-19.

Este texto no pretende llegar a conclusiones definitivas sobre el tratamiento de la emigración en todos los medios españoles. Somos conscientes de que se analizan unos pocos textos, de unos pocos diarios y de que un análisis completo implicaría otros diarios de diferentes sensibilidades. Por otra parte, haría falta una mayor contextualización de la 
problemática migratoria, incluyendo el análisis de la legislación vigente y las diferentes situaciones que experimentan los emigrantes. Sin embargo, consideramos que los textos que aquí reunimos y analizamos pueden ser un comienzo en el camino de desvelar la relación entre fenómeno migratorio y una situación de crisis como la provocada por el coronavirus, así como las vinculaciones, inevitables, entre los poderes públicos, políticos, económicos y sociales. Por otra parte, nos anima a publicar este avance el hecho de haber encontrado discursos que no siempre estereotipan, estigmatizan y criminalizan al emigrante, como si la relación entre pandemia y emigración permitirá sacar a la luz otras reflexiones que no siempre están en el centro del debate político.

\section{DESCRIPCIÓNYCONTEXTUALIZACIÓNDELOS DISCURSOS INFORMATIVOS}

La llegada de este virus, en primera instancia, avivó un resquemor hacia la población asiática, por ser, supuestamente, la principal y originaria portadora del virus. En las charlas cotidianas se vislumbraba cierto rechazo, lo que propagó el estigma de las personas provenientes de Asia; en concreto, de China, como población estigmatizada por antonomasia. Sin embargo, es notorio que apenas se publicaron noticias en las que se citara tal nacionalidad cuando se hablaba de "migración", o similares.

Desde medios como El País se ha apostado por la presentación de noticias que tomaban la pandemia como una oportunidad, tanto para el gobierno de España como para las personas migrantes. Se trataba de cambiar "un modelo migratorio roto" y reformarlo, sobre todo, en lo que respecta a la regularización en el ámbito laboral. A primeros de mayo se plantea la situación provocada por el Covid-19 como una puerta para los mercados de trabajo; esto, también, desde una visión beneficiosa para la población nacional, pues se habla de "extranjeros como insustituibles" en el sistema español. Bien es cierto que el autor del texto periodístico pone de manifiesto el discurso habitual en muchos medios de comunicación que alude a una "migración ordenada":

"La verdadera receta contra la inmigración irregular no son las concertinas, sino un sistema ordenado, flexible y exigente que se ajuste a las señales del mercado y optimice los beneficios de este fenómeno para todas las partes involucradas".

Sin embargo, este artículo de El País habla de entender mejor la diversidad de "nuestras audiencias", haciendo alusión a que los trabajadores migrantes "no necesitan caridad, sino de sistemas legales sólidos y predecibles que garanticen derechos y oportunidades". A diferencia de las múltiples informaciones cuantitativas sobre el coronavirus, en este caso se da mayor peso a los relatos de vida de las personas y no tanto a las cifras. El texto periodístico termina aludiendo a que, a pesar de la incertidumbre, la covid-19 fomenta la unión "para frenar los contagios, para encontrar una vacuna y para reiniciar nuestras economías”.

2. https://elpais.com/elpais/2020/05/02/3500 millones/1588412499 348286.html 
$\mathrm{Al}$ respecto de este último, merece mención la atención que se presta a los "extranjeros", en este caso, como insustituibles porque contribuyen y resultan beneficiosos al Estado al que llegan, por lo que pasan a ser también "sostenedores" de todo el sistema. En cambio, en la mayoría de ocasiones, se menciona a los "inmigrantes" que llegan en patera (es frecuente que se especifique este modo de llegada), y que no disponen de ningún tipo de material de protección y están en aras de "ser llevados a" y "sostenidos por".

En la misma línea de comprender la migración como "oportunidad", se articula la noticia cuyo título es "Inmigrantes al rescate", que tiene por subtítulo "La crisis del coronavirus ha revelado que no existe futuro para los sistemas de salud de los países ricos sin la contribución de los profesionales extranjeros"3. En el texto se presenta cómo ha sido precisa una pandemia para destapar las carencias del sistema sanitario. Retomando el tema terminológico, se habla, en la mayoría de casos, de "inmigrantes", y no de "extranjeros", como parte integrante y resolutiva, potencialmente, de los problemas que acontecen a España. También se manifiesta cómo situaciones de pandemia como la de la covid-19 revelan distintos escenarios a consecuencia de esta crisis sanitaria global, en cuestiones de migración:

"El Gobierno de España había anunciado antes de esta catástrofe su intención de racionalizar la política migratoria para cubrir las necesidades futuras de nuestro mercado de trabajo. Ha hecho falta una tragedia, pero ahora sabemos dónde tenemos un buen agujero y quién puede ayudarnos a cubrirlo. El hecho de que la Administración haya sido capaz de cambiar tan rápido el paso, solo demuestra el escaso interés desplegado hasta ahora".

Un artículo de El Mundo, de mediados de abril, parece denunciar el doble estigma que se genera al relacionar el coronavirus con la inmigración. En él se hace mención a "refugiados que fueron rechazados por un alcalde del PP y que son utilizados por VOX para construir agravios"4. Se pone sobre la mesa el peligro de mostrar la otredad asociada a discursos que sugieren la idea del negro que viene a infectarnos. El artículo relata cómo a instancias de los mencionados políticos se trasladan discursos de odio como los que narran que la llegada de refugiados en tiempos del Covid-19 supone ocupar espacios como hoteles de lujo, además de recibir materiales sanitarios, como si esto fuera en detrimento de la población nacional. En este artículo también se desentrañan bulos (algo que también está muy próximo siempre a las noticias sobre migración) como, por ejemplo, que estas personas habrían sido interceptadas por la Cruz Roja, cuando en realidad intervinieron otras entidades. En definitiva, se denuncia cómo se vincula el coronavirus y la migración creándose imágenes y discursos negativos:

3. https://elpais.com/sociedad/2020-04-01/inmigrantes-al-rescate.html

4. https://www.elmundo.es/andalucia/2020/04/19/5e9b202dfc6c836d4b8b4625.html 
"Refugiados, familias con hijos, que tratan de construir un futuro mejor y que en los últimos días han sido objeto de una campaña de rechazo tras detectarse siete casos de coronavirus en el centro dependiente de la Cruz Roja de Almería al que fueron trasladados a principios de año. Una polémica aderezada con ignorancia y desinformación; carnaza para discursos políticos de baja estofa en tiempos de pandemia”.

Los artículos analizados también reflejan una vinculación estrecha en asuntos de migración, coronavirus y gobernanza, y que desvelan, a su vez, incertidumbre. En $E l$ País, en el mes de mayo, y dada la situación de rescate que se estaba llevando a cabo en el Mar de Alborán y en el puerto de Motril, se alude a carencias gubernamentales como fueron los planes de cuarentena y sus repercusiones en los temas migratorios.

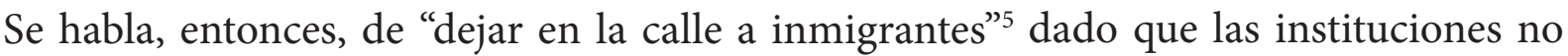
habían previsto y, por tanto, no habían habilitado, ningún lugar para las personas que llegaban. Asimismo, como denuncia Natalia García Caballos, miembro de la Asociación Pro Derechos Humanos de Andalucía (APDHA),

"llegaron sin mascarillas ni ningún elemento de protección", se lamenta. [...] "A las tres y pico de la madrugada, y andando más de 40 minutos, llegamos con los 13 inmigrantes al segundo pabellón que nos ofrecieron, donde finalmente han pasado la noche". El pabellón les ha servido de techo para la noche, pero poco más. "El sitio estaba especialmente sucio y no había nada. Tres colchonetas. Nada de comida, agua, toallas o mantas. Tampoco mascarillas. Pero allí se quedaron, encerrados, porque cerraron la puerta con llave", describe Natalia García".

Algunos textos periodísticos ponen el foco en los "espacios de encierro". Un artículo publicado en El País a comienzos del estado de alarma, en el mes de marzo, expone cómo "las restricciones por el coronavirus paralizan las expulsiones de inmigrantes", y subtitula: "Ante la imposibilidad de devolverles a sus países, el Defensor del Pueblo pide la liberación de los internados en los CIE"7.

No son pocos los artículos que aluden al fenómeno migratorio en términos de "control social" y "orden estatal". Es frecuente vincular estas nociones con las de coronavirus y migraciones. Por un lado, se responsabiliza a los gobiernos de cuestiones de esta índole, sin criminalizar a las personas migrantes. Por otro, se desvelan debilidades y carencias de

5. https://elpais.com/espana/2020-05-25/la-ausencia-de-un-plan-de-cuarentena-obliga-a-dejar-en-lacalle-a-inmigrantes.html

6. https://elpais.com/espana/2020-05-25/la-ausencia-de-un-plan-de-cuarentena-obliga-a-dejar-en-lacalle-a-inmigrantes.html

7. https://elpais.com/espana/2020-03-19/las-restricciones-por-el-coronavirus-paralizan-lasexpulsiones-de-inmigrantes.html. CIE son las siglas de Centro de Internamiento de Extranjeros. 
los Estados que se ven "vulnerables" en situaciones de incertidumbre, como la provocada por una pandemia. Asimismo, se alude a ciertos vacíos legales y se habla, incluso, de retenciones ilegales:

"El Defensor del Pueblo mantiene una posición similar. En el caso de los extranjeros internados en un CIE, se da la particularidad de que su privación de libertad tiene como fin exclusivo asegurar la materialización de su devolución o expulsión. Las circunstancias actuales impiden que se pueda dar cumplimiento a esta finalidad por lo que, a juicio del Defensor del Pueblo, estas personas deben ser puestas en libertad".

Al hilo de los lugares "controlados", en El Mundo se relata que el Ministerio de Interior "acelera el trámite para la expulsión de inmigrantes que llegaron en una patera con coronavirus". En este artículo queda de manifiesto cómo la pandemia tiene un alto impacto en cuestiones migratorias y cómo salen a la luz las debilidades de los Centros de Internamiento de Extranjeros (CIE), ya que en situaciones como la acontecida en España en el mes de abril, "los llegados en la patera no van a ser internados en el CIE de la isla ni como suele suceder cuando el CIE está completo, en instalaciones penitenciarias, ante el riesgo de que generen contagios". En cierto sentido, queda patente el doble estigma: son emigrantes e infectados, a la vez. Las personas que llegan son llevadas a otras dependencias y acogidas por Cruz Roja, puesto que otras instituciones han sido alertadas del riesgo. He aquí una alusión interesante en tanto en cuanto la Sociedad del riesgo (Beck, 1998) es construida en función de las amenazas, reales o virtuales.

Si reflexionamos sobre la matriz narrativa del riesgo durante la pandemia, debemos mencionar a Mairal (2013), puesto que cuando nos encontramos ante incertidumbres, los medios de comunicación fomentan la idea de riesgo. Además, sistematizan hechos como potencialmente recurrentes. Desde la prensa se insta a pensar que tales acontecimientos pueden volver a producirse. Tanto es así que los relatos son especulativos y frecuentemente giran en torno a probabilidades de que algo dañino ocurra. Cabe recordar con Mairal la distinción entre riesgo y peligro. El primero tiene temporalidad y es, por tanto, controlable. El segundo, sin embargo, ya supondría la presencia del daño. ¿Cómo se ha presentado entonces el fenómeno migratorio en términos de salud pública en los artículos de prensa escrita analizados?

En El País, en un artículo publicado en abril, se presenta el peligro en relación a lo que se va, a lo que huye, a raíz del coronavirus y más en concreto del parón económico acontecido en España. Las tornas se invierten y el artículo relata cómo la pandemia fuerza movimientos migratorios, con mediación de "5.000 euros por escapar de España

8. https://www.elmundo.es/espana/2020/04/04/5e8784c021efa018268b45a7.html 


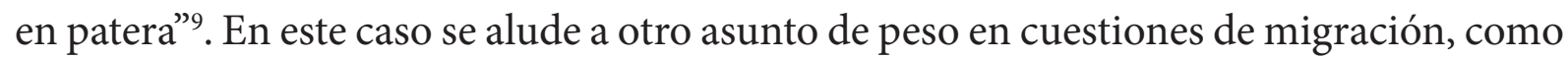
es el del tráfico de personas: "Un grupo de unos 100 marroquíes se embarcó a finales de marzo en dos botes inflables para volver de forma clandestina a su país y burlar las restricciones decretadas para frenar el virus tanto en España como en Marruecos"10. Se habla así del retorno, pero de uno forzado por la coyuntura de salud pública. En todo caso, los traficantes humanos sacan provecho, como se especifica en un documento de la Comisión Europea ${ }^{11}$.

"Los traficantes de migrantes muestran extrema flexibilidad y adaptabilidad de sus negocios delictivos, ahora también organizando los viajes de migrantes marroquíes irregulares que huyen de la Covid-19 en dirección opuesta, es decir, de España a Marruecos"12.

El artículo se hace eco de términos muy interesantes como el que verbalizó Rita Hatimi, diputada parlamentaria, y que aludía a la "contra-migración ilegal", a consecuencia de la problemática de salud pública, y el brote de virus pertinente en España, además de la falta de oportunidades laborales.

Junto a estas "huidas" y la búsqueda de vías de "escape", también encontramos textos que hablan del descenso de "entradas irregulares", que caen casi la mitad durante la pandemia. En un artículo de primeros de mayo se especifica que Canarias es la única ruta migratoria con actividad y se muestran estadísticas que presentan con datos los porcentajes migratorios en comparación con años anteriores:

"Siguen las llegadas de pateras a la Península y Baleares que han caído un 75\% durante este periodo. Del 16 de marzo al 3 de mayo, han desembarcado 279 personas frente a las 1.094 del mismo periodo del año anterior. Las 122 entradas por tierra a través de la valla y las fronteras de Ceuta y Melilla, suponen una caída del $84 \%$ respecto a los mismos días del año anterior"13.

Abundan los textos que ponen énfasis en diversas carencias en las políticas de migración. Un artículo de El País se refiere a la falta de recursos adecuados de acogida a consecuencia de un "positivo en coronavirus de un grupo de inmigrantes en Soria":

9. https://elpais.com/espana/2020-04-23/mas-de-5000-euros-por-escapar-de-espana-en-patera.html

10. https://elpais.com/espana/2020-04-23/mas-de-5000-euros-por-escapar-de-espana-en-patera.html

11. https://www.consilium.europa.eu/es/policies/migratory-pressures/managing-migration-flows/

12. https://elpais.com/espana/2020-04-23/mas-de-5000-euros-por-escapar-de-espana-en-patera.html

13. https://elpais.com/espana/2020-05-05/las-entradas-irregulares-caen-casi-la-mitad-durante-la-pandemia.html 
"Siete positivos por coronavirus en dos pisos de acogida para inmigrantes en Soria han expuesto la falta de recursos apropiados para acoger a los recién llegados y garantizar el aislamiento de 14 días al que deben someterse todos los viajeros procedentes del exterior. Los contagios se han producido al desplazar a un grupo de seis inmigrantes que recalaron en patera en Almería a dos apartamentos en Soria en los que ya vivían otras personas. La Fundación Cepaim, la organización designada por la Secretaría de Estado de Migraciones para su traslado y acogida, reconoce que debería haber acomodado a los recién llegados en una vivienda vacía, pero asegura que no fue posible porque el sistema no cuenta con las plazas suficientes "para atender todas las necesidades derivadas de la Covid-19"14.

En este artículo se presenta que no hay un protocolo definido de actuación en estos casos, lo que impide el preciso aislamiento, a modo de prevención. Dos semanas después de la publicación del decreto que establecía la "cuarentena obligatoria de todos los viajeros procedentes del exterior", resultaba imposible cumplir dicha normativa. Una vez más, se manifiestan responsabilidades; en este caso, las autoridades competentes de los ámbitos de Sanidad y Migraciones. Se denuncia que no habría consenso para la actuación. Sin embargo, de nuevo entra a colación la migración problematizada como estructural en cuestiones de acogida: "El protocolo, en cualquier caso, es una hoja de ruta que no resuelve el problema estructural de plazas de acogida para atender a los migrantes, una carencia agravada ahora por las exigencias de aislamiento de la pandemia"15.

En otro artículo de El País, en el mes de mayo, se manifiesta claramente la necesidad de control por parte del gobierno español para que "los migrantes" guarden cuarentena, y lo ejemplifica haciendo un símil: "Al igual que los viajeros que lleguen a España desde el extranjero" ${ }^{16}$. Asimismo, se atiende a la carencia de espacios de acogida, que debieron habilitarse para que se dieran las medidas de seguridad sanitaria adecuadas:

"Queremos pensar que el Gobierno se está poniendo manos a la obra para dar una solución, porque aquí no nos planteamos si vendrán pateras o no vendrán, solo cuándo vendrán. Llegan sí o sí”, afirma José Luis Guedes, secretario general del Sindicato Unificado de Policía (SUP) en Canarias. La Comisión Española de Ayuda al Refugiado (CEAR) ha pedido un protocolo urgente para garantizar no solo la

14. https://elpais.com/espana/2020-06-02/el-positivo-en-coronavirus-de-un-grupo-de-inmigrantes-en-soria-expone-la-falta-de-recursos-adecuados-de-acogida.html

15. https://elpais.com/espana/2020-06-02/el-positivo-en-coronavirus-de-un-grupo-de-inmigrantes-en-soria-expone-la-falta-de-recursos-adecuados-de-acogida.html

16. https:/elpais.com/espana/2020-05-15/el-gobierno-estudia-como-garantizar-que-los-migrantes-llegados-en-patera-guarden-cuarentena.html 
salud, sino también los derechos de los migrantes. "Deben hacer una cuarentena con toda la dignidad que debería tener cualquier ciudadano", pidió un portavoz"17.

En aras de esta horizontalidad, en un artículo de El País, en el mes de junio, y casi al finalizar el estado de alarma, se presenta un ejemplo transcontinental que pretende compartir información, desde la radio, sobre el covid-19: "Un programa hecho por jóvenes desde España y Senegal ayuda a difundir información veraz y sensibilizar sobre la pandemia y cómo afecta en uno y otro país"18. En este caso se destaca la necesidad de contextualización, además de mostrar la importancia de las historias de vida, que se vinculan, a su vez, con situaciones de incertidumbre y de crisis social. "Se ve la migración de otra forma, ven que hay otra realidad en la que antes no se fijaban, que las cosas funcionan según la situación del momento", afirma el locutor [...]. "La manera de ayudar ahora es contar esta realidad y, sobre todo, sensibilizar explicando cómo lo viven allí y llamando la atención a los que están aquí para que no se relajen", añade Amadou. Para este locutor, que habla y convive a diario con los vecinos de Gandiol (Senegal), testimonios como el de Serigne son muy importantes porque ayudan a que la gente no olvide que la pandemia es real.

\section{ANÁLISIS Y REFLEXIONES FINALES}

El análisis de algunos artículos de prensa española durante la pandemia en relación a los emigrantes revela el uso reiterado de varios términos significativos que ya se utilizaban antes de la crisis sanitaria: "patera", "irregularidad", "ilegalidad", "efecto llamada", etc. Con la nueva situación pandémica irrumpe otro término que se vuelve a asociar al emigrante: "contagio". En algunos casos, se conforman narrativas que amplifican el miedo y la alarma social; "personas contagiadas llegan", "sin protección". Se presenta el fenómeno migratorio sustancialmente como "problema" que dificulta el control y el orden (buscado y esperado) por el Estado. La cuestión migratoria es motivo de incertidumbre, máxime cuando pone de manifiesto la falta de recursos. La pandemia trae consigo también hechos sociales paradójicos, como que las personas migrantes anhelen el retorno como vía de escape por beneficio propio, dadas las carencias del Estado y la situación de vulnerabilidad del emigrante.

Los emigrantes constituyen, por lo tanto, un problema añadido. Esos "otros" ya eran percibidos como una amenaza, pero ahora se modifica algo su supuesto peligro: no solo provienen de "fuera" de las fronteras nacionales, sino que están "fuera" del sistema ordenado, controlado, homogéneo, seguro. La situación anormal, inesperada y el descontrol generan la búsqueda de culpables y esos "otros" parecen estar magníficamente

17. ttps://elpais.com/espana/2020-05-15/el-gobierno-estudia-como-garantizar-que-los-migrantes-llegados-en-patera-guarden-cuarentena.html

18. https://elpais.com/elpais/2020/06/10/planeta futuro/1591779163 022471.html 
bien situados para ejercer de chivos expiatorios: se recalca en algunas noticias su naturaleza de "contagiados" y "contagiosos".

Sin embargo, lo más sorprendente de los artículos analizados es que hay bastantes que presentan la vulnerabilidad de las personas migrantes. En ocasiones, los medios fomentan una representación de estas como "víctimas", retomando esa dualidad de "sostenedores" y "sostenidos". Los emigrantes serían no solo víctimas de una situación de desamparo provocada por la pobreza, la falta de empleo, etc., sino que ahora la pandemia posiciona a los sujetos migrantes como "necesitados de cuidados".

La pandemia provoca otra cuestión que se problematiza en los medios de comunicación: las incongruencias y limitaciones de las normativas, los protocolos administrativos, las posibilidades de un Estado para salvaguardar la integridad de los emigrantes. En ese contexto de vulnerabilidad aumentada, surgen discursos que hablan de "diversidad", "cohesión" y proponen entender la ciudadanía en un sentido más amplio, dada la situación de pandemia: todos estaríamos amenazados, todos seríamos víctimas. El emigrante es una persona igual de amenazada que el resto. Es más: padece las limitaciones del Estado.

Es en ese contexto que algunos discursos mediáticos consideran el fenómeno migratorio como "oportunidad" en tiempos de coronavirus, dadas las contribuciones que precisa un país como España para los sistemas de salud, por ejemplo. Sin embargo, cabría cuestionarse: ¿Quién sale beneficiado de este anhelo por cubrir las necesidades futuras de nuestro mercado de trabajo? ¿Se trata de una anexión de fuerzas para un bien común? ¿Es más bien una manera utilitarista de ver, y justificar, la migración?

En la mayoría de casos, las noticias sobre la covid-19 muestran cifras, porcentajes, una vertiente cuantitativa que aleja las historias vitales, las cuales, sin embargo, sí están presentes en la representación mediática del fenómeno migratorio cuando surgen narrativas que ponen en el centro la diferencia, la desigualdad, las mayores dificultades de los emigrantes.

Así pues, el fenómeno migratorio en el contexto del coronavirus sugiere dos discursos antagónicos. Por un lado, los emigrantes son vistos como un peligro, una amenaza, un problema, en gran medida aumentado, y en ese sentido, "fabricado" en una situación en que el público consume noticias alarmantes. Sin embargo, parece que la construcción de la diferencia y los procesos clasificatorios se resignifican en un contexto como el de la pandemia, dado que no encontramos solamente discursos estigmatizadores que pueden aumentar la discriminación, el rechazo, la exclusión, el odio, la xenofobia y el racismo. En este artículo hemos puesto énfasis, sobre todo, en la existencia de otro tipo de discursos que recalcan su situación de vulnerabilidad, de víctimas, de sujetos desamparados que también deberían ser considerados en sus derechos más elementales, incluso que podrían ser vistos como agentes sostenedores de un sistema que se tambalea. 
Naturalmente, somos conscientes de que la focalización sobre solo dos diarios específicos supone un sesgo que no permite una visión global. Sin embargo, resulta esperanzador que durante la pandemia no se hayan recreado solamente discursos estigmatizantes y que el emigrante no haya sido en exclusividad diana del miedo, la incertidumbre y la ira, como era plausible pensar antes de iniciar una investigación que solo será concluyente cuando se analicen muchos otros medios de comunicación. 


\section{REFERENCIAS BIBLIOGRÁFICAS}

Bañón Hernández, Antonio Miguel (2014) "Medios de comunicación e inmigración. Aproximación a una línea de investigación consolidada”. En Cristina Blanco Fernández de Valderrama (ed.), Movilidad humana y diversidad social en un contexto de crisis económica internacional. Madrid: Trotta, pp. 111-135.

Beck, Ulrich (1998) La sociedad del riesgo: Hacia una nueva modernidad. Barcelona: Paidós.

Cortina, Adela (2017) Aporofobia, El rechazo al pobre. Un desafío para la democracia. Madrid: Paidós.

Díaz de Rada, Ángel (2010) Cultura, antropología y otras tonterías. Madrid: Trotta.

Domingo, Andreu (2018) Demografía y posverdad. Estereotipos, distorsiones y falsedades sobre la evolución de la población. Barcelona: Icaria.

Galindo, Jorge (2015) "El concepto de riesgo en las teorías de Ulrich Beck y Niklas Luhmann". Acta Sociológica, 67: 141-164.

Giddens, Anthony (1997) Consecuencias de la modernidad. Madrid: Alianza.

Mauss, Marcel (2009) Ensayo sobre el don. Forma y función del intercambio en las sociedades arcaicas. Buenos Aires: Katz.

Mairal Buil, Gaspar (2013) La década del riesgo. Situaciones y narrativas de riesgo en España a comienzos del siglo XXI. Madrid: Los Libros de la Catarata.

Zizek, Slavoj (2020) Pandemic! Covid-19 shakes the world. Barcelona: Anagrama. 